\title{
Úlcera por pressão em idosos hospitalizados: informações ao cuidador informal
}

\author{
Flávia da Silva Gatto*, Selma Petra Chaves Sá, D.Sc.**
}

*Residente de Enfermagem no Hospital Geral de Bonsucesso, Área de Concentração: Enfermagem Clínica e Cirúrgica Geral pela Universidade Federal do Estado do Rio de Janeiro, UNIRIO, **Professora Titular do Departamento de Fundamentos de Enfermagem e Administração da Escola de Enfermagem Aurora de Afonso Costa da Universidade Federal Fluminense, UFF

\begin{abstract}
Resumo
Os idosos, quando restritos ao leito, apresentam risco elevado de desenvolvimento das úlceras por pressão. Os objetivos do estudo foram identificar se os idosos acamados, com a presença de cuidadores informais, desenvolvem ou não as úlceras por pressão e levantar informaçóes dadas aos cuidadores dos idosos hospitalizados sobre prevenção de úlceras por pressão. Estudo de natureza qualitativa exploratória, através de estudo de caso. Foi realizado com dez cuidadores informais primários, de idosos hospitalizados restritos ao leito, em um Hospital Universitário. Dos dez idosos, seis desenvolveram úlceras por pressão. A partir das falas dos sujeitos, emergiram duas categorias: "cuidadores primários de idosos informados sobre úlceras por pressáo e as respectivas informaçôes" e "orientaçôes variadas aos cuidadores sobre açôes no espaço físico hospitalar e com seu idoso". É de grande importância as orientaçôes fornecidas pelo enfermeiro, visando à prevenção das úlceras por pressão através de medidas simples que o cuidador pode realizar.
\end{abstract}

Palavras-chave: úlcera de pressão, idoso, cuidadores, acompanhamento de pacientes.

\section{Abstract \\ Pressure ulcers in the elderly: information to the caretakers}

Elderly people, when restricted to their hospital beds, show a higher risk of developing pressure ulcer. The study aimed at: a) identifying whether bedridden elderly, being taken care informally, will develop pressure ulcer and, b) collecting data with hospital caretakers regarding the prevention of pressure ulcers. This was a qualitative exploratory study, done through case study. It was performed with ten informal primary caretakers responsible for hospitalized abed elderly, at a University Hospital. From the ten elderly in the study, six developed pressure ulcers. From what was heard from patients, two categories emerged: "elderly primary caretakers informed about pressure ulcers" and "various orientations to caretakers about procedures at hospitals and their elderly patients". The information given by nurses is extremely important, aiming at preventing pressure ulcers through simple measures which can be taken by caretakers.

Key-words: pressure ulcer, elderly, caretakers, patient follow-up. 


\section{Resumen \\ Úlcera por presión en ancianos hospitalizados: informaciones al cuidador informal}

Los ancianos, cuando se encuentran obligados a estar en cama, presentan riesgo elevado de desarrollar úlceras por presión. Los objetivos de este estudio fueron identificar si los ancianos en cama, ante la presencia de cuidadores informales, desarrollan o no las úlceras por presión y recopilar las informaciones que se les dan a los cuidadores de los ancianos hospitalizados acerca de la prevención de úlceras de presión. Se trata de un estudio de naturaleza cualitativa exploratoria, a través de un estudio de caso. Se realizó con diez cuidadores informales primarios de ancianos hospitalizados, obligados a estar en cama, en un Hospital Universitario. De los diez ancianos, seis desarrollaron úlceras de presión. A partir de los discursos de los sujetos del estudio, surgieron dos categorías: "cuidadores primarios de ancianos informados sobre úlceras de presión y sus respectivas informaciones" y "orientaciones variadas que se les dan a los cuidadores sobre acciones en el espacio físico hospitalario y con relación al anciano bajo sus cuidados". Las orientaciones proporcionadas por el enfermero son de suma importancia, puesto que lo que se pretende es la prevención de las úlceras de presión por medio de medidas sencillas que el cuidador puede realizar.

Palabras-clave: úlcera por presión, anciano, cuidadores, acompañantes de pacientes.

\section{Introdução}

Sabemos que a população idosa vem crescendo a cada dia, e com o envelhecimento cresce também o número de doenças crônico-degenerativas, o que nos leva a pensar em um grande número de internaçóes de idosos. E entre estes idosos internados o surgimento das úlceras por pressão é um fator de risco. Aproximadamente $2 \%$ dos pacientes hospitalizados adquirem úlceras por pressão durante a internação [1].

No cotidiano nos deparamos com um grande número de idosos internados e a relação estreita com o desenvolvimento das úlceras por pressão. Estes idosos muitas vezes estão acompanhados por cuidadores (formais ou informais). O estudo teve como objeto a ação do cuidador informal, ou seja, aquele que usualmente é um membro da família, amigos ou voluntários da comunidade.

Pensamos que se o cuidador for informado acerca dos cuidados que ele pode desenvolver, essas açóes podem refletir na melhora da qualidade de vida, diminuição do tempo de internação e prevenção de úlceras por pressão no idoso hospitalizado, além de contribuir com o cuidado da equipe de enfermagem.

Assim, este artigo teve como objetivos identificar se os idosos acamados, com a presença de cuidadores informais, desenvolvem ou não as úlceras por pressão e, levantar quais informaçóes são dadas aos cuidadores dos idosos hospitalizados sobre prevenção de úlceras por pressão.

\section{Pele e envelhecimento}

A pele é o mais extenso órgão do corpo humano. É uma forma de barreira entre os órgãos internos e o ambiente externo, impede a perda de líquidos, penetraçáo de substâncias, microorganismos e de radiaçóes ultravioletas do sol. Com o envelhecimento, estas funçôes decaem, tornando a pele mais suscetível às agressóes do meio ambiente, podendo ocorrer inúmeras alteraçóes quanto à textura, à elasticidade, à espessura, à resistência ao atrito, à pigmentação, à secreção sebácea, ao conteúdo hídrico, entre outras [2].

Com o envelhecimento, há diminuição dos vasos sanguíneos, em número e tamanho, acarretando em uma diminuição da função imunológica, o que facilita as infecçôes e retardam a cicatrização das feridas; a diminuição dos receptores cutâneos leva os idosos a apresentar menor percepçáo da temperatura ambiente e de suas variaçóes e diminuição da sensibilidade tátil; ocorre diminuição da atividade das glândulas sudoríparas e sebáceas, proporcionando no idoso, pele seca, áspera e descamativa, e mais sensível às variaçóes de temperatura do meio ambiente [3] e às agressóes externas como, por exemplo, a pressão.

As camadas epiderme e derme tornam-se finas e achatadas levando à formaçáo de rugas, arqueamentos e sobreposição das dobras cutâneas. Este adelgaçamento das camadas contribui para um aumento na vulnerabilidade ao trauma da pele senil, onde até os menores traumas podem provocar equimoses com manchas vermelhas ou púrpuras salientes 
ou até mesmo a separação entre as duas camadas. $\mathrm{O}$ tecido subcutâneo, com o passar do tempo, perde substâncias como a gordura subcutânea, diminuindo a proteção e o acolchoamento dos tecidos e órgãos subjacentes, além do tônus muscular e das propriedades de isolamento térmico [3].

\section{Úlceras por pressão}

As úlceras por pressão são definidas como "áreas localizadas de injúria tecidual que se desenvolvem quando o tecido mole permanece comprimido entre uma proeminência óssea e uma superfície externa, durante um período de tempo prolongado" [4].

Aparecem em poucos dias e progridem rapidamente. "A chance de um paciente desenvolver uma úlcera tende a aumentar à medida que aumenta o tempo de institucionalizaçáo" [1].

A interação entre intensidade e duração da pressáo a qual o tecido é submetido parece ser determinante no desenvolvimento das úlceras por pressão [5]. Porém, pacientes que permanecem por um curto período de tempo expostos à uma alta pressão também podem sofrer danos parecidos àqueles que permanecem sobre pressão por longos períodos [6].

$\mathrm{E}$ os idosos, quando restritos ao leito, apresentam risco elevado de desenvolvimento das úlceras de pressão devido a fatores extrínsecos como, por exemplo, fricção, cisalhamento, umidade e, a fatores intrínsecos como as alteraçóes na pele comuns no envelhecimento, doenças crônico-degenerativas, ingesta nutricional inadequada, entre outros.

\section{Cuidadores informais de idosos}

Existem dois tipos de cuidador, o cuidador formal, ou seja, exercido por um profissional que convive com o idoso parte do dia e é remunerado, e o cuidador informal, aquele náo-profissional, geralmente um familiar que convive com o idoso, na maioria das vezes, em horário integral ou parte do dia $[7,8]$.

O cuidado informal pode ser prestado pela família, amigos, vizinhos e membros da comunidade, porém é a família que predomina neste sistema [9] Assim, quando um idoso é internado ou precisa de cuidados em casa, a família ou um de seus membros é eleito para cuidar deste idoso.

Os cuidadores informais podem ser classificados como primários, secundários e terciários. Os cuidadores primários são os principais responsáveis pelo idoso e pelo cuidado; os cuidadores secundários não apresentam o mesmo nível de responsabilidade e decisão, mas realizam algumas tarefas básicas como, por exemplo, ajuda doméstica e transferência e os cuidadores terciários são coadjuvantes e não têm responsabilidade pelo cuidado, são aqueles que, por exemplo, fazem compras e pagam as contas [8].

Os estudos revelam que embora a designação do cuidador seja informal, o processo de cuidar segue quatro fatores: parentesco - com freqüência maior para os cônjuges, antecedendo sempre a presença de um filho; gênero - com predominância para a mulher; proximidade física - considerando quem vive com a pessoa que requer os cuidados e proximidade afetiva - destacando a relação conjugal e a relação entre pais e filhos [10]. E em relação à faixa etária dos cuidadores, freqüentemente, pertencem à mesma geração dos doentes. "São 'idosos jovens independentes' cuidando de 'idosos dependentes”' [9]. Existe uma norma social implícita segundo a qual cabe aos filhos e aos cônjuges cuidar dos idosos, o que explica a idade dos cuidadores [8].

Assim, é importante para o idoso hospitalizado, o envolvimento tanto afetivo quanto de prestaçáo de cuidados dos seus cuidadores.

\section{Material e métodos}

A proposta metodológica do estudo é de natureza qualitativa exploratória, através de estudo de caso. A pesquisa foi realizada em três unidades de internação, sendo duas clínicas médicas e uma clínica cirúrgica de um hospital universitário. As pesquisadoras levantaram todos os idosos internados no período de um mês, no ano de 2006, e que estivessem acompanhados por cuidador informal pelo menos por um período de quatro horas diariamente.

A partir da seleção de 10 sujeitos, realizou-se um levantamento nos prontuários dos seguintes dados: nome; idade; $\mathrm{n}^{\mathrm{o}}$ do prontuário; tempo de hospitalização e diagnóstico.

Após essa etapa, procedeu-se a inspeção na pele do idoso com o intuito de identificar a presença ou náo de úlcera por pressão e classificá-la quanto ao seu estágio de desenvolvimento, quando presente. E quando necessário, os dados coletados foram confirmados com o enfermeiro da clínica.

Para os cuidadores dos idosos realizou-se uma entrevista semi-estruturada que foi gravada 
e constou de dados para identificação e questóes como: grau de parentesco e/ou ligação afetiva com o idoso hospitalizado, tempo de atuação como cuidador informal, tempo de permanência no hospital com o idoso, informaçôes sobre úlceras por pressão, informaçóes sobre suas açóes com o idoso durante a hospitalização e quais profissionais têm mais contato ou retiram dúvidas acerca das açóes que desenvolve.

Os sujeitos foram identificados por letras do alfabeto. Todos os cuidados éticos foram tomados, inclusive com a assinatura do Termo de Consentimento Livre Esclarecido por parte dos cuidadores.

\section{Resultados e discussão}

Os dados coletados sobre o idoso e os de identificação dos seus cuidadores contribuíram para a análise dos dados. Após leitura e releitura das entrevistas, foi possível separar os temas emergentes e, a partir disso, elaborou-se duas categorias: "Cuidadores primários de idosos informados sobre úlceras por pressão e as respectivas informações" e "Orientaçôes variadas aos cuidadores sobre açôes no espaço físico hospitalar e com o idoso”.

\section{Informaçóes coletadas sobre o idoso}

Dos 10 (dez) idosos internados, 8 (oito) são do sexo feminino e 2 (dois) do sexo masculino. As mulheres estão incluídas na faixa etária de 60 a 100 anos, com predomínio de 70 e 80 anos. E os homens estáo incluídos somente entre 70 e 80 anos. Dados demográficos apontam que as mulheres vivem de seis a sete anos mais que os homens [11]. As mulheres estão vivendo mais, entretanto não se pode afirmar que isto ocorra com qualidade, as chances de surgimento das doenças crônicas, possivelmente, podem aumentar. O grande desafio, nos dias atuais, é fazer com que essa longevidade seja acompanhada de qualidade de vida, pois a prevalência de doenças crônicas tem aumentado significativamente, principalmente nas mulheres idosas [12].

Seis (6) idosos desenvolveram úlcera por pressão entre os quais, 3 (três) desenvolveram durante a hospitalização e 3 (três) no domicílio. Esse achado nos mostra que os idosos apresentam risco elevado para o desenvolvimento das úlceras por pressão [1].

A partir do conhecimento dos fatores de risco para o desenvolvimento das úlceras por pressão, das medidas de prevenção e da alta prevalência de úlceras nos idosos acamados, tornam-se de suma importância as orientaçóes que o cuidador de idosos deve receber durante a hospitalização de seu idoso. Essas orientações também são importantes serem reforçadas no momento da alta hospitalar, evitando as úlceras no domicílio e conseqüentemente a rehospitalização.

Ao comparar o tempo de hospitalização com o desenvolvimento ou não da úlcera por pressão pode-se observar que dos 3 (três) idosos com menor tempo de internação (até uma semana), 2 (dois) desenvolveram úlcera por pressão durante a atual hospitalizaçáo e o idoso que mais tempo se encontrava hospitalizado (mais de quatro semanas) também desenvolveu a lesão. A relação entre intensidade e duração da pressão pode ser diretamente ou inversamente proporcional. Uma alta pressão com longa duração ou uma alta pressão com curta duração são determinantes para o desenvolvimento das úlceras por pressão, mas apesar da pressão ser o fator etiológico primário [4], existem outros fatores que predispóem o desenvolvimento das úlceras por pressão, entre eles os fatores intrínsecos relacionados às variáveis do estado físico do paciente [13], pois o corpo pode enfrentar uma pressáo externa maior quando está saudável do que quando está doente [14].

Em relação às regióes em que os idosos internados desenvolveram as úlceras por pressão, a região sacra foi o local de maior prevalência totalizando 4 (quatro) úlceras, sendo uma em estágio I, duas em estágio II e uma em estágio IV. Não foi encontrada úlcera em estágio III. As outras regiôes foram calcâneo, trocânter e maléolo. As áreas de proeminência óssea estáo mais propensas ao desenvolvimento das úlceras por pressão devido ao peso do paciente estar totalmente concentrado nessas partes durante o repouso prolongado em superfície inadequada [6], como as macas e colchóes hospitalares padróes.

Os idosos, no momento da internaçáo, apresentavam um grande número de doenças crônicodegenerativas como câncer, hipertensão, demência, dentre outras. A elevada prevalência de doenças crônico-degenerativas, associada à decorrência de pluripatologia, pode ser considerada responsável pela necessidade de maior permanência hospitalar e pela progressiva perda de autonomia dos idosos [15], além de ser um fator de risco para o desenvolvimento das úlceras por pressão [16]. 


\section{Caracterizaçáo dos cuidadores}

Dos 10 (dez) cuidadores, 9 (nove) são do sexo feminino e 1 (um) do sexo masculino. A tarefa de cuidar dos idosos é realizada pela família e quando esses idosos se tornam doentes ou dependentes, os maiores encargos cabem às mulheres [11].

Historicamente, a mulher tem papel de subordinação, destinada a procriar, amamentar e cuidar do marido. Para cuidadoras esposas, o ato de cuidar está embutido no seu papel de mulher casada, a partir do compromisso assumido e selado desde o momento do matrimônio [11]. Logo, a responsabilidade de cuidar de um membro da família dependente é visto como mais uma tarefa natural associada à sua função biológica [10]. Na perspectiva do gênero, do ponto de vista cultural, há uma definição de campos específicos para a atuação feminina e outro com privilégios para a atuação masculina. Além disso, no ocidente ainda vincula a mulher à natureza e o homem à cultura [17].

Em relação às faixas etárias, 2 (dois) cuidadores encontram-se na faixa de 20 a 30 anos e 8 (oito) cuidadores na faixa de 40 a 50 anos. $O$ cuidador familiar, geralmente, é uma mulher de meia idade, seja esposa, filha ou nora [12]. Pode-se observar que, essencialmente, os cuidadores de idosos também são adultos maduros ou estão em uma faixa etária próxima dos 60 anos de idade, o que mostra que pessoas entrando na terceira idade estão cuidando de idosos. São velhos-jovens independentes cuidando de velhos-velhos dependentes [10]. E também são candidatos a doenças crônico-degenerativas devido à sua faixa etária.

A maioria dos cuidadores apresenta parentesco próximo ao idoso, sendo 4 (quatro) filhas e 1 (um) filho; 2 (duas) cuidadoras são netas; 1 (uma) cuidadora é afilhada e 2 (duas) cuidadoras são noras. Pode-se observar, então, que quando um idoso necessita de cuidados, geralmente, um dos membros da família assume esse cuidado. O cuidado ao idoso dependente ainda é de responsabilidade da família e geralmente os filhos adultos assumem este papel, ou por vínculo afetivo, ou por responsabilidade culturalmente incorporada da obrigação dos filhos em cuidar de seus pais, ou por não terem outra opção de cuidado, até mesmo por não disporem de condiçôes para delegar esse cuidado a alguém [12].

A maioria dos cuidadores náo apresenta experiência de cuidado prévio, com outros idosos. A experiência desses cuidadores se resume em cuidar do próprio idoso hospitalizado, uma vez que apresentam parentesco próximo ao idoso, ou seja, são familiares. Apenas 1 (um) cuidador apresentou experiência anterior em cuidar de outro idoso que não aquele hospitalizado. Dados indicam que já ter sido cuidador aumenta muito as chances de vir a sê-lo novamente, quando necessário [8].

Em relação ao tempo de atuaçáo como cuidador do idoso, 1 (um) cuidador atua junto ao idoso no período de 4 (quatro) meses, ou seja, passou a prestar o cuidado antes da internação do idoso, devido à doença; 4 (quatro) cuidadores passaram a prestar cuidado ao idoso no período de sua internaçáo, ou seja, menos de 4 (meses) e 5 (cinco) cuidadores já cuidavam de seus idosos, antes da internação. $\mathrm{O}$ tempo que cada cuidador dispensa ao idoso teve uma relação com a coabitação entre eles, visto que a maioria mora no mesmo domicílio. Desemprego, divórcio, viuvez, filhos que náo saem nunca de casa: essas são as razóes que explicam por que, no Brasil, as geraçóes mais velhas coabitam cada vez mais com as geraçōes mais jovens [18].

Um (1) cuidador permanece em média 3 dias na semana no hospital; 2 (dois) cuidadores ficam todos os dias, ou seja, em tempo integral; a grande maioria, 6 (seis) cuidadores, permanece metade do dia e 1 (um) não tem dia fixo de permanência. $\mathrm{O}$ cuidado constante dispende do cuidador praticamente todo o seu tempo, as suas forças, o seu lazer e até suas emoçóes [19]. E isso pode gerar conflitos e sobrecarga nos cuidadores. Para um filho que cuida de seus pais os conflitos podem ser maiores, pois os projetos de vida são diferentes e terão que ser redefinidos ou até mesmo abandonados em função do cuidado familiar.

Quanto à escolaridade, três (3) cuidadores cursaram o nível superior, 5 (cinco) o nível médio e 2 (dois) o nível fundamental. O nível de escolaridade desses cuidadores aponta para uma possível facilidade de compreensão a respeito da doença que o idoso apresenta e sobre os cuidados que podem ser desenvolvidos pelos próprios cuidadores no ambiente hospitalar junto ao idoso dependente, cuidados estes, orientados pela equipe de enfermagem.

\section{Cuidadores primários de idosos informados sobre úlceras por pressáo e as respectivas informaçóes}

Ao serem questionados sobre a definição de úlcera por pressão e a mobilização como elemento primordial para a prevençáo das mesmas, observa-se 
que dos 10 (dez) sujeitos, 2 (dois) indicam, pelas suas falas, ter noção do que seja uma úlcera por pressão quando citaram alguns fatores de risco para o desenvolvimento das mesmas, tais como: imobilidade, pressão x tempo, fragilidade da pele idosa, fricção/cisalhamento e desidratação. Tal afirmação pode ser comprovada pelas seguintes falas:

"O contato direto com a cama a pele fica fina, desidratando [...].”. ( A)

"É uma lesão causada por muito tempo que a pessoa permanece deitada naquela posição, a pressão do próprio corpo por muitas horas, eu classifico assim." (C)

O reconhecimento dos fatores de risco que um paciente acamado pode estar sujeito é de suma importância, pois ajudará no desenvolvimento efetivo de estratégias de prevenção, permitindo que a equipe de enfermagem junto ao cuidador desenvolva medidas preventivas para que as úlceras por pressão não se desenvolvam nos idosos restritos ao leito [4].

O conhecimento prévio das úlceras por pressão pode estar relacionado ao nível de escolaridade dos cuidadores e não exclusivamente pelas informaçóes fornecidas pela equipe de saúde. Tal afirmação se efetiva devido às seguintes falas:

"Leio, tento me informar." (A)

"Leitura, também informação verbal.” (C)

$\mathrm{Na}$ caracterização dos sujeitos, observou-se a escolaridade dos cuidadores, sendo que a metade dos entrevistados possui nível médio e alguns cuidadores nível superior, e isto é um fator que contribui para que as informaçóes se disseminem com maior freqüência, apesar de náo terem experiência anterior com o cuidado ao idoso. Assim, se explica o fato de citarem alguns fatores de risco para o desenvolvimento das úlceras por pressão e demonstrarem que sabem, sem grande aprofundamento, que úlcera significa uma lesão e/ou ferida na pele.

De um modo geral, as pessoas encarregadas pelo cuidado apresentam pouco preparo para exercer tal papel [8]. Precisam de apoio e estímulo dos profissionais, como a equipe de enfermagem, para proporcionar maior qualidade nos cuidados prestados aos idosos, prevenindo o aparecimento de úlceras por pressáo. Como a úlcera por pressáo no idoso leva a inúmeras complicaçóes, podendo chegar à morte, a equipe de saúde deve informar, estimular e supervisionar náo somente a mudança de decúbito, mas os outros cuidados primordiais para minimizar o aparecimento e/ou eliminação das úlceras por pressão em idosos.

Em relação à mudança de posição para evitar o surgimento das úlceras por pressão foram citadas algumas medidas preventivas: mudança de decúbito freqüente (3 sujeitos); proteção de proeminências ósseas com travesseiros (1 sujeito); hidratação da pele com o uso de creme (1 sujeito). As falas abaixo apontam para tais medidas:

"Sei que tem que mudar ela, a cada três horas [...]." (C)

"Coloco travesseiro com a área de maior contato, calcanhar, no meio da perna." (A)

Observa-se que a maioria dos cuidadores se detém a mudança de decúbito como único cuidado para a prevenção das úlceras por pressão, desconhecendo inúmeros outros cuidados como a mobilização do idoso no leito, evitar a umidade da pele pelas incontinências, estimular a nutriçáo e outros. As medidas preventivas devem fazer parte do cuidado diário aos idosos acamados pela equipe de enfermagem e também pelo cuidador.

Três (3) sujeitos citam que a mudança de decúbito evita o surgimento de "escaras", como descrito abaixo:

"A pessoa tem que ir mudando de lado, eu sempre mudo, coloco ela de lado, se não vai dando escaras, o que sei é só isso." (E)

"A gente tem que mudar de meia em meia hora, de uma em uma hora se não fica com escara." (J)

Pode-se observar que os cuidadores ao citarem o termo "escara" estão referindo-se às feridas que ocorrem na pele dos idosos acamados, ou seja, as úlceras por pressão. No hospital observamos que este termo ainda é utilizado também por profissionais da área de saúde, porém deve ser relacionado exclusivamente à presença de crosta necrótica na lesão [1].

De acordo com algumas falas observa-se que existe uma certa percepçáo por parte do cuidador do que seja, o que causa e o que deve ser feito para evitar as úlceras por pressão nos seus idosos. En- 
tretanto, alguns idosos desenvolveram úlceras (6 idosos), e isto pode ser contraditório. Tal fato pode ocorrer devido a dificuldades que o cuidador tem em saber ou de ser informado até onde pode chegar referente ao cuidado no espaço hospitalar, além das condiçóes intrínsecas para o desenvolvimento de úlceras por pressão.

$\mathrm{O}$ cuidador deve ser orientado e estimulado pelo enfermeiro sobre medidas simples que deve executar junto ao idoso no ambiente hospitalar. Também deve receber informaçôes sobre o por quê de tais medidas, para executá-las de forma mais eficaz.

A partir do momento que o cuidador está informado, estimulado e se propóe a realizar os procedimentos para evitar as úlceras por pressão dentro do hospital, após a alta do seu idoso, estará em condiçóes de desenvolvê-las em casa também, evitando assim, que o idoso desenvolva úlcera por pressão no domicílio, como é o caso de três idosos da pesquisa. A educação dos cuidadores é fundamental, pois teráo o suporte necessário para dar continuidade aos cuidados visando à prevençáo [16].

\section{Orientaçóes variadas aos cuidadores sobre açóes no espaço físico hospitalar e com seu idoso}

Ao serem questionados sobre as orientaçóes fornecidas pela equipe de saúde acerca das ações desenvolvidas na área física hospitalar e aquelas possíveis de serem desenvolvidas junto aos idosos, observa-se que apenas 1 (um) cuidador recebeu orientação acerca das açóes desenvolvidas na área física hospitalar. $\mathrm{Na}$ fala abaixo, o sujeito relata ter recebido por escrito o que poderia fazer dentro do hospital:

"Me deram um papel. O acompanhante deve evitar contato com outros pacientes para não transferir de um lado para o outro [...]." (A)

De fato existe um folheto para autorização de "Acompanhamento de Pacientes", elaborado pela Diretoria de Enfermagem, onde possui algumas orientaçóes para o acompanhante e deve ser fornecido pelo enfermeiro responsável pelo setor onde o idoso encontra-se internado. Vale ressaltar que no folheto, além de dados de identificaçáo do cuidador, tem o local para que o enfermeiro do setor assine autorizando a permanência do cuidador com o idoso. $\mathrm{O}$ folheto também possui informaçóes como uso de avental, lavagem das mãos, tempo de permanência no ambiente além de frases que apontam a possibilidade da ajuda do cuidador durante os cuidados.

Em relação às orientaçóes sobre as açóes com o idoso no hospital, dos 10 (dez) cuidadores, 5 (cinco) relatam ter sido orientados. Entre as informações, a mudança de decúbito foi citada por 3 (três) cuidadores, sendo orientada pela enfermeira, auxiliar de enfermagem e pelo médico, conforme as falas abaixo:

\section{"A enfermeira fala para está virando de lado para não dá ferida nas costas, para ficar mu- dando de posição, só isso que sei.” (D) \\ "A médica informou para colocar a paciente sentada." (A)}

Outras informaçóes foram evidenciadas como não mexer no soro/medicaçáo citada por 1 (um) cuidador e chamar a enfermeira quando necessário por 2 (dois) cuidadores. Essas informaçóes foram concedidas por enfermeiros, segundo os cuidadores. As orientaçóes podem ser evidenciadas nas seguintes falas:

\footnotetext{
"Conforme eu fui cuidando dela. Pode fazer uma coisa, não pode mexer no soro, náo posso mexer na medicação. Tem que chamar a enfermeira. A enfermeira que falou, que essas coisas não podia mexer, tem que chamar." (F)
"Se precisar de alguma coisa falar com a enfermeira que ela ajuda, se precisar trocar a fralda que ela ajuda." $(\mathrm{G})$

Parece existir uma contradição entre as falas dos sujeitos, pois para que o cuidador permaneça no hospital é preciso ter a autorizaçáo em mãos, ou seja, o folheto. Provavelmente o cuidador não se interessou e não foi estimulado a ler o que está contido no mesmo e esclarecer as suas dúvidas com o enfermeiro do setor, apenas se contentou em receber um papel assinado autorizando a sua entrada no ambiente hospitalar.

A leitura da população não é estimulada por levar ao pensamento crítico, a contestação e a transformaçáo, elementos esses que colocam em 
risco a estrutura social vigente [20], o que pode explicar o desinteresse da população brasileira pela leitura.

Apesar dos cuidadores receberem pouca ou nenhuma orientação em relação ao espaço físico e com o idoso no hospital, ao serem questionados sobre quais profissionais têm mais contato ou retira dúvidas acerca das açóes e atividades dentro do hospital, todos citam algum profissional e apontam, a maioria, para a equipe de enfermagem. Tal afirmação pode ser comprovada pelas falas abaixo:

"Poucas informaçôes. Conforme eu fui cuidando dela [...]. Normalmente a gente vai tirando as dúvidas com as enfermeiras de plantão.” (F)

"Isso é por nossa conta. A parte da enfermagem, auxiliar de enfermagem.” (I)

Tal situação fica evidente uma vez que é a equipe de enfermagem quem atua vinte e quatro horas por dia junto aos pacientes e seus cuidadores. Apesar da existência do folheto, ficou evidenciado que não é chamado à atençáo do cuidador para a sua leitura e não são destacados pontos importantes para o cuidado que este acompanhante pode realizar com seu idoso no hospital, além do desinteresse por parte do cuidador em ler o que recebeu.

\section{Conclusão}

O avanço da ciência da saúde vem contribuindo para o aumento da expectativa de vida da população, porém as doenças da infância responsáveis pela morte precoce, atualmente controladas, estáo sendo substituídas pelas doenças crônico-degenerativas que acompanham o envelhecimento. Os idosos que são internados com tais doenças têm as chances aumentadas de desenvolver as úlceras por pressão, ao se tornarem acamados.

De acordo com o levantado, pode-se observar que há pouca informação fornecida ao cuidador a respeito do que pode ou não ser realizado dentro do hospital e junto ao seu idoso. E que, apesar da equipe de enfermagem ter maior contato com os cuidadores, visto que prestam assistência durante vinte e quatro (24) horas por dia aos idosos, os cuidadores são pouco estimulados a realizarem açóes de prevenção das úlceras por pressão. Tais orientaçóes se resumem à mudança de decúbito freqüente.
Os cuidadores possuem um conhecimento prévio do que seja úlcera por pressão e das feridas que podem surgir na pele do idoso acamado e que não foram, exclusivamente, fornecidas pelos membros da equipe de saúde. Conhecem alguns fatores de risco como a pressão, a fragilidade da pele idosa, a imobilização, entre outros, e algumas medidas preventivas como a mudança de decúbito freqüente, proteção das proeminências ósseas, hidratação da pele. Porém, os idosos acompanhados por seus respectivos cuidadores desenvolveram úlceras por pressão, tanto durante a hospitalização quanto no próprio domicílio.

Como a maioria dos cuidadores permanece metade do dia junto ao idoso hospitalizado, a equipe de enfermagem deve ter um olhar diferenciado em relação à figura do cuidador, tendo-o como aliado, pois este pode contribuir com o trabalho da equipe através de medidas simples que podem realizar. $\mathrm{O}$ enfermeiro pode orientar os cuidadores quanto às suas açôes dentro do hospital e junto ao idoso no que diz respeito às úlceras por pressão. E o cuidador estando mais esclarecido, irá colaborar com o que pode ser feito ou não.

\section{Referências}

1. Marini MF. Úlcera de pressão. In: Freitas EV, et al. Tratado de geriatria e gerontologia. Rio de Janeiro: Guanabara-Koogan; 2002.

2. Curiati JAE, Alencar YMG. Aspectos da propedêutica do idoso. In: Carvalho Filho ET, Papaléo Netto, M. Geriatria: fundamentos, clínica, terapêutica. São Paulo: Atheneu; 1994.

3. Smeltzer RC, Bare, BG. Histórico da função tegumentar. In: Smeltzer RC, Bare, BG. Brunner e Suddarth: Tratado de enfermagem médico-cirúrgica. 10a ed. Rio de Janeiro: Guanabara-Koogan; 2005.

4. Goode PS, Allman RM. Úlceras de pressão. In: Calkins E, Ford A, Katz PR. Geriatria prática. 2a ed. Rio de Janeiro: Revinter; 1997.

5. Rangel EML. Conhecimento, práticas e fontes de informação de enfermeiros de um hospital sobre a prevenção e tratamento da úlcera de pressão [dissertação]. Ribeirão Preto: Escola de Enfermagem de Ribeirão Preto, USP; 2004.

6. Costa IG. Incidência de úlcera de pressão e fatores de risco relacionados em pacientes de um centro de terapia intensiva. [Dissertação]. Ribeirão Preto: Escola de Enfermagem de Ribeirão Preto, USP; 2003.

7. Pacheco JL. O cuidador: sua instância e sua experiência. In: Saldanha AL, Caldas CP, eds. Saúde do idoso: a arte de cuidar. 2a ed. Rio de Janeiro: Interciência; 2004.

8. Neri AL, Carvalho VAML. O bem-estar do cuidador: aspectos psicossociais. In: Freitas EU, et al. Tratado de 
geriatria e gerontologia. Rio de Janeiro: GuanabaraKoogan; 2002.

9. Caldas CP. Cuidado familiar: a importância da família na atenção à saúde do idoso. In: Saldanha AL, Caldas CP, eds. Saúde do idoso: a arte de cuidar. 2 a ed. Rio de Janeiro: Interciência; 2004.

10. Mendes PBMT. Cuidadores: heróis anônimos do cotidiano. [Dissertação]. São Paulo: PUC; 1995.

11. Silva IP. As relaçóes de poder no cotidiano de mulheres cuidadoras. In: Karsch UM, ed. Envelhecimento com dependência: revelando cuidadores. São Paulo: EDUC; 1998.

12. Varoto VAG, Truzzi OMS, Pavarini SCI. Programas para idosos independentes: um estudo sobre seus egressos e a prevalência de doenças crônicas. Texto \& Contexto Enfermagem 2004;13(1):107-14.

13. Silva MSML. Fatores de risco para úlcera de pressão em pacientes hospitalizados [dissertação]. Paraíba: UFPA; 1998.

14. Dealey C. O tratamento de pacientes com feridas crônicas. In: Dealey C. Cuidando de feridas: um guia para as enfermeiras. São Paulo: Atheneu; 1996.

15. Duarte MJRS. Atenção ao idoso: um problema de saúde pública e de enfermagem. Rev Enfermagem UERJ 1994;2(1):100-11.

16. Barros MCD. O cuidador leigo na a prevenção da úlcera por pressão em idosos no domicílio. [Dissertação]. Rio de Janeiro: UFRJ; 2005.

17. Sá SPC. Idoso: representação social da velhice e as implicaçóes no cuidado de si [tese]. Rio de Janeiro: UFRJ; 2004.

18. Peixoto CE. Aposentadoria: o retorno ao trabalho e solidariedade da família. In: Peixoto CE. Família e envelhecimento. Rio de Janeiro: Fundação Getúlio Vargas; 2004.

19. Thober E, Creutzberg M, Viegas K. Nível de dependência de idosos e cuidados no âmbito domiciliar. Rev Bras Enfermagem 2005;58(4):438-43.

20. Silva ET. Leitura ou "lei-dura"? In: Abreu M, ed. Leituras no Brasil: antologia comemorativa pelo $10^{\circ}$ cole. São Paulo: Mercado de Letras; 1995. 